\title{
Appendix 4: Qualitative Survey
}

Background question: What is your current role and which unit/organization do you represent?

1. In which ways do you participate in the process of learning from current and past CSDP missions and operations?

2. How do you expect to learn from CSDP [Common Security and Defence Policy] missions and operations? What are the lessons that you look for?

3. How do you participate with others in routines of learning from CSDP missions and operations (e.g., meetings, seminars, workshops, and exercises)?

4. What happens to the knowledge produced through assessments and evaluations of CSDP missions and operations? For example, do you write reports or produce other types of material to preserve the knowledge?

5. Can you give an example of a successful process of lessons learned from CSDP missions and operations? 